\title{
PELATIHAN KREASI TAS GONI DARI LIMBAH PASAR UNTUK MENINGKATKAN NILAI EKONOMI PRODUK
}

\author{
Zakiah Hidayati*, Cisyulia Octavia Helikopta Simanjuntak \\ Prodi Arsitektur, Politeknik Negeri Samarinda \\ email: zakitec@yahoo.co.id
}

\begin{abstract}
We are facing a lot of environmental issue right now. One of the environmental problem is household and industrial waste such as plastic. Plastic waste is becoming a widely recognised environmental problem. The government of Samarinda has been banned plastic bags in grocery stores in order to reduce plastic waste as determined by Mayor Regulation No. 8 of 2019. Lots of people are looking for reusable shopping bag. One of the alternative to plastic grocery bag is burlap bag. The traditional market sellers often sell their grain in burlap sacks and may be willing to give away the unusable sacks. Burlap is very useful and has many specific application, like grocery bag and pouch. Burlap grocery bag can be adorned with patch, embroidery and beads. The aim of community service is to teach housewives to design and apply patch onto the burlap grocery bag, as traditional market waste, in order to increase the value of product. The result of the class is : improved their skill in designing and creating patch on burlap bag. It is hoped that the class will support the potential of creativity industry by reusing the waste material.
\end{abstract}

Kata Kunci: creation, burlap bag, waste

\begin{abstract}
Abstrak
Kita menghadapi banyak persoalan lingkungan yang salah satunya adalah limpahan sampah plastik. Berbagai cara dilakukan untuk mengurangi sampah plastik. Pemerintah Kota Samarinda, melalui Perwali Samarinda No 1 Tahun 2019 mengeluarkan kebijakan terkait pengurangan penggunaan kantong plastik di supermarket. Masyarakat Samarinda pun mau tak mau mencari tas belanja alternatif yang ramah lingkungan. Dasar pertimbangan pemilihan material tas adalah mudah didapat, mudah terurai oleh bumi dan berasal dari barang bekas. Salah satu barang bekas yang dapat dimanfaatkan sebagai tas belanja adalah karung goni. Tas karung goni yang didesain menarik tentu akan meningkatkan nilai produk tersebut, baik itu nilai fungsi, estetika dan ekonomi. Salah satu cara meningkatkan penampilan tas karung goni adalah dengan penambahan ornamen, patchwork dan sulam. Tujuan kegiatan pengabdian ini adalah memberi pelatihan kreasi ornamen pada tas karung goni, melalui kombinasi warna dan bentuk, untuk Ibu-ibu Rumah Tangga. Metode pelatihan dengan ceramah, diskusi, tanya jawab, demonstrasi, dan workshop. Hasil kegiatan pengabdian adalah target materi pelatihan tersampaikan dengan baik karena teknik kreasi ornamen dikuasai dengan baik oleh peserta. Produk hasil pelatihan pun cukup menarik dan berpotensi untuk dikembangkan sebagai produk komersil. Diharapkan dengan pelatihan ini membuka potensi industri kreatif di lingkungan rumah tangga.
\end{abstract}

Kata Kunci: kreasi, tas goni, sampah

\section{PENDAHULUAN}

Isu lingkungan hidup menjadi salah satu isu terpenting dalam kehidupan masyarakat di berbagai belahan dunia. Dampak lingkungan yang rusak telah dirasakan hampir seluruh masyarakat dunia. Berbagai cara, telah dan sedang dilakukan sebagian masyarakat untuk mengurangi dampak kerusakan lingkungan, misalnya dengan pengurangan penggunaan plastik, penanaman pohon, pengurangan pemakaian energi. Kontribusi masyarakat 
dalam pengurangan dampak kerusakan lingkungan diharapkan dapat dilakukan secara berkesinambungan dan kreatif.

Pemerintah daerah di Indonesia pun secara bertahap telah membuat kebijakankebijakan yang diharapkan dapat berkontribusi positif terhadap lingkungan. Pun demikian dengan Pemerintah Kota Samarinda yang melalui Peraturan Walikota Samarinda No 1 Tahun 2019 telah mengeluarkan kebijakan terkait pengurangan penggunaan kantong plastik pada supermarket dan toko modern (PemkotSamarinda, 2019). Masyarakat Samarinda pun mau tak mau mencari tas alternatif ramah lingkungan untuk membawa barang belanja yang dapat dipakai dalam jangka waktu lama.

Samarinda memiliki pasar-pasar tradisional yang menghasilkan limpahan karung goni yang biasa digunakan untuk mengangkut bahan-bahan pangan seperti kentang, jagung, kopi dan sebagainya. Sebagian karung-karung goni tersebut umumnya digunakan kembali oleh pedagang dan lainnya justru menumpuk tak terpakai dan bahkan sebagian dibuang begitu saja.

Pengolahan dan pemanfaatan karung goni masih terbatas dan tidak sebanding dengan semakin banyaknya jumlah karung goni bekas. Hal ini karena sebagian besar orang cenderung menggunakan karung sintetis yang dirasa jauh lebih praktis (Sulistiyoningrum, Jufrizal, \& Mulia, 2017).

Kita tahu bahwa karung goni dapat dimanfaatkan menjadi benda-benda lain yang berguna, seperti tatakan gelas, kantong sovenir dan tas belanja yang sekarang semakin dibutuhkan masyarakat. Sampah-sampah organik ini bisa dimanfaatkan menjadi produk kerajinan yang memiliki nilai ekonomi. Sehingga kita bisa berpartisipasi melakukan perbaikan lingkungan sekaligus mendapatkan manfaat ekonomi. Hal ini dapat menjadi instrumen bagi pemerintah daerah dalam melakukan pembinaan dan pemberdayaan ekonomi masyarakat (Marzuki \& Ali, 2018).

Pembuatan produk kerajinan berbahan sampah telah dilakukan oleh beberapa kelompok masyarakat namun belum menjadi sesuatu yang dimasukkan dalam sistem pengelolaan sampah (Fatoni, Imanuddin, \& Darmawan, 2017). Bahkan sebagian masyarakat masih ada yang belum paham mengolah sampah secara sederhana, misalnya membuat sampah organik rumah tangga menjadi kompos (Nurdin \& Silmi, 2014). Artinya ini termasuk pekerjaan rumah bagi kita untuk mensosialisasikan pemanfaatan sampah menjadi sesuatu yang lebih berguna.

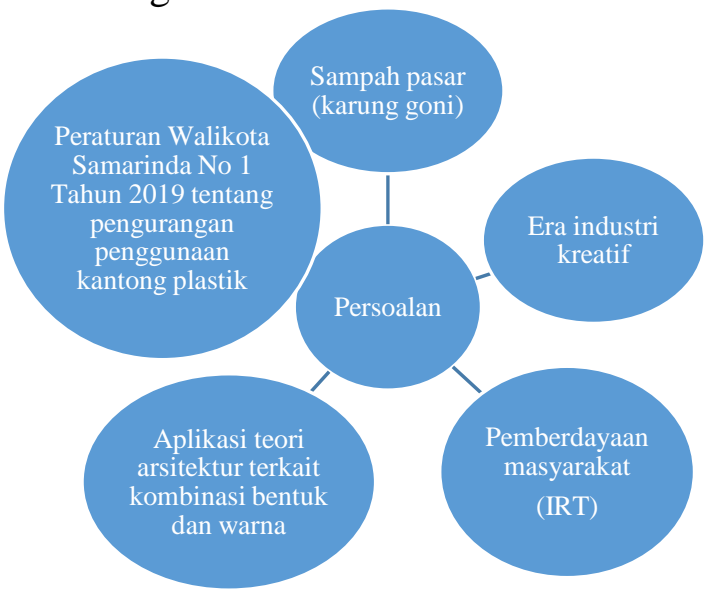

Gambar 1. Persoalan

Era industri kreatif sekarang ini, kegiatan di bidang desain menjadi kegiatan yang sangat diperhitungkan. Kerajinan karung goni mampu memberdayakan warga sekitar. Contohnya di Desa Gedepangrango, Kecamatan Kadudampit, Kabupaten Sukabumi. Adanya industri kerajinan goni mampu memberi manfaat ekonomi kepada warganya (Iman, 2017).

Sektor ekonomi masyarakat berupa UKM juga dapat meningkat dengan adanya kegiatan kreatifitas untuk meningkatkan nilai jual dari barang bekas. Salah satu yang disasar adalah kemampuan wirausaha Ibu Rumah Tangga agar dapat meningkatkan penghasilan keluarga (Hadi, Darwin, Widiarsih, Hidayat, Murialti, \& Asnawi, 2017).

Di Indonesia, kebijakan yang mengatur tentang industri kreatif dituangkan Instruksi 
Presiden RI nomor 6 Tahun 2009 tentang Pengembangan Industri kreatif. Kebijakan ini ditujukan untuk mengembangkan perekonomian rakyat yang bertumpu pada kreativitas, keterampilan, dan bakat individu untuk menciptakan daya kreasi dan daya cipta individu yang bernilai ekonomis dan berpengaruh pada kesejahteraan masyarakat Indonesia. Adapun lingkup industri kreatif antara lain periklanan, arsitektur, desain, musik dan kerajinan (Rochani, 2017).

Arsitektur tidak sekedar kegiatan desain yang berhubungan dengan kota, kawasan, bangunan atau lanskap, tetapi juga terkait dengan kegiatan olah rasa (terkait dengan bentuk, warna, tekstur dan lain-lain). Ilmu arsitektur mempelajari tentang teori komposisi bentuk, warna dan tekstur. Kegiatan olah rasa inilah yang diperlukan dalam industri kreatif.

Industri kreatif adalah industri potensial yang dapat dilakukan oleh semua segmen masyarakat dengan fokus pada kreasi dan inovasi, seperti Ibu Rumah Tangga, remaja putus sekolah, anak-anak yatim piatu, dan lansia. Diperlukan pemberdayaan masyarakat melalui kegiatan keterampilan.

Pimpinan Daerah 'Aisyiyah Kota Samarinda selanjutnya disebut PDA Kota Samarinda, adalah salah satu organisasi di kota Samarinda yang mengkhususkan diri pada amal usaha di bidang kesehatan, kesejahteraan sosial, ekonomi dan pemberdayaan masyarakat. Permasalahan yang dihadapi PDA Kota Samarinda cukup beragam. Salah satu permasalahan khusus adalah terkait dengan pemberdayaan masyarakat. PDA Kota Samarinda memiliki program kerja yaitu mengadakan kerjasama dengan institusi di luar untuk pemberdayaan masyarakat di lingkungan PDA Kota Samarinda berupa kegiatan seminar atau pelatihan.

Salah satu yang dapat diajarkan oleh Program Studi Arsitektur Politeknik Negeri Samarinda (Polnes) adalah kreasi flanel pada tas dari limbah karung goni dari pasar dengan menerapkan teori kombinasi bentuk dan warna bagi ibu-ibu rumah tangga di
Kecamatan Samarinda Ulu. Peserta pelatihan keterampilan ini adalah Ibu Rumah Tangga yang tergabung dalam pengajian/kegiatan yang dikelola Pimpinan Daerah 'Aisyiyah (PDA) Kota Samarinda.

\section{METODE PENGABDIAN}

Metode yang digunakan dalam kegiatan pengabdian berupa pelatihan kreasi flanel pada tas karung goni adalah dengan:

1. Metode ceramah dan diskusi.

Memberikan teori tentang alternatif bahan tas belanja selain plastik, cara meningkatkan estetika pada karung goni, dan alat dan bahan yang digunakan. Metode pembelajaran adalah ceramah dan diskusi dengan menggunakan media LCD.

2. Metode demonstrasi.

Metode demontrasi berupa contoh pembuatan kreasi flanel pada tas karung goni langsung dihadapan peserta.

3. Metode praktik

Peserta mempraktikkan pembuatan kreasi flanel pada tas karung goni didampingi langsung oleh asisten instruktur.

4. Metode evaluasi

Metode evaluasi berupa berupa umpan balik dari peserta pengabdian masyarakat.

Evaluasi pelatihan adalah upaya untuk mengetahui tingkat keterlaksanaan program, atau untuk mengetahui implementasi dari suatu kebijakan. Dengan demikian kegiatan evaluasi pelatihan mengacu pada tujuan sebagai ukuran keberhasilan (Widyastuti \& ES, 2015).

Evaluasi dilakukan setelah kegiatan utama berakhir. Alat ukurnya dengan menggunakan berbagai cara, misalnya kuesioner, wawancara, dan observasi. Direncanakan kegiatan evaluasi pada pelatihan ini dilakukan dengan menyebar kuesioner kepada seluruh peserta dengan pertanyaan-pertanyaan terkait dengan pelatihan keterampilan yang telah diselesaikan. Keberlanjutan program juga 
termasuk hal yang ditanyakan di dalam kuesioner. Jika dianggap perlu dilanjutkan maka Prodi Arsitektur akan mencoba mengajukan proposal kegiatan pelatihan sesuai skim dan syarat ketentuan dari institusi Polnes.

\section{HASIL DAN PEMBAHASAN}

Pelatihan dilakukan dilakukan di salah satu amal usaha 'Aisyiyah yaitu di aula Panti Asuhan 'Aisiyah Al Walidaturrahmah, dengan peserta Ibu-ibu Rumah Tangga di Kecamatan Samarinda Ulu yang tergabung di pengajian Pimpinan Daerah 'Aisyiyah Kota Samarinda.

Peserta kegiatan sesuai target berjumlah 15 orang IRT dan setiap 3 orang peserta akan didampingi oleh asisten instruktur. Asisten instruktur ini adalah mahasiswamahasiswa Prodi Arsitektur yang akan membantu peserta terkait dengan pola bentuk dan warna.

Acara pembukaan dihadiri oleh Pimpinan Daerah 'Aisyiyah Kota Samarinda, seluruh staf Prodi Arsitektur, peserta, instruktur dan beberapa mahasiswa Prodi Arsitektur.

Peserta diberi materi oleh instruktur utama dan diberikan alat dan bahan untuk membuat kreasi aplikasi pada tas karung goni yang dibuat dari sisa limbah pasar di tempat.

Selanjutnya adalah kegiatan mendesain dan membuat patch dari kain flanel dengan fokus pada bentuk dan warna. Tema desain bebas, bisa berupa ornamen tradisional, bentuk geometris, flora dan lain sebagainya. Proses desain cukup memakan waktu karena mereka antusias berdiskusi mencari desain favorit masing-masing.

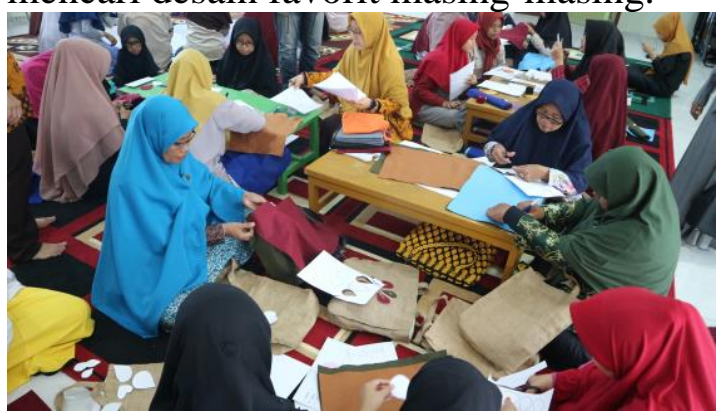

Gambar 2. Proses desain dan pembuatan patch
Ukuran patch tidak boleh terlalu kecil agar tidak menyulitkan ketika menggunting dan menjahit kain flanel.

Masing-masing patch terdiri dari dua lembar kain flanel agar mencapai ketebalan yang cukup. Tepi-tepi patch dijahit dengan teknik feston agar lebih rapi dan awet, menggunakan benang dan jarum khusus sulam kain.

Peserta antusias dengan kegiatan ini. Mereka kreatif dalam membuat ornamen bebas. Instruktur dan asisten instruktur memberikan arahan terkait dengan pola warna dan bentuk yang diaplikasikan.

Pada tahapan menjahit patch yang sudah jadi, peserta yang semuanya merupakan IRT, cukup terampil dalam mengaplikasikan ke tas goni. Patch dijahit dengan membentuk komposisi yang menarik sehingga tas karung goni menjadi lebih bernilai estetika dan layak untuk dikomersilkan di kemudian hari.

Karya-karya peserta Ibu Rumah Tangga ini cukup baik dan menarik. Ide desain patch terlihat unik dan otentik. Mereka nantinya dapat mengembangkan kreasi patch dengan material yang berbeda seperti benang rami, kain perca, kancing baju dan lain-lain.

Acara ditutup dengan evaluasi kegiatan oleh peserta. Peserta sangat mengapresiasi kegiatan ini dan berharap akan diadakan kegiatan lanjutan dari Prodi Arsitektur.

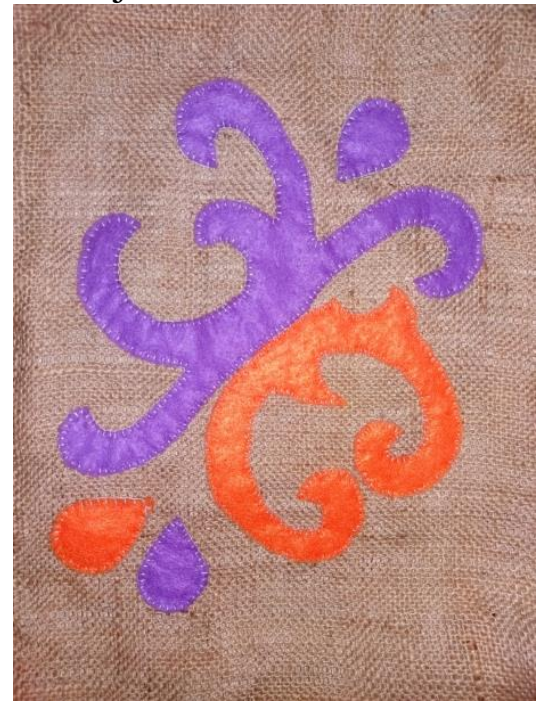

Gambar 3. Salah satu karya ornamen patch 
Diharapkan peserta dapat berkarya dengan tingkat yang lebih tinggi lagi dan menjadikannya sebagai peluang berbisnis di kemudian hari.

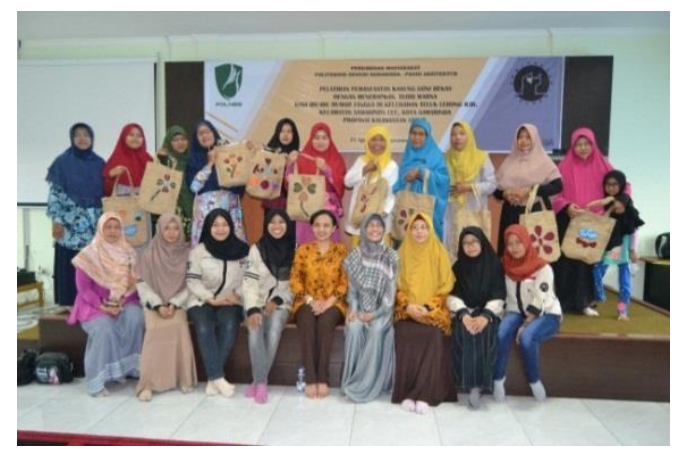

Gambar 4. Sebagian peserta dan hasil karyanya

\section{SIMPULAN}

Kesimpulan dari kegiatan PKM yaitu pelatihan kreasi flanel pada tas dari hasil limbah pasar (karung goni) adalah :

1. Menambah wawasan pada Ibu-ibu Rumah Tangga tentang pengetahuan mengolah bahan bekas karung goni menjadi alternatif tas belanja.

2. Menambah keterampilan pada Ibu-ibu Rumah Tangga untuk lebih kreatif dalam meningkatkan kualitas suatu produk atau barang.

3. Membuka peluang bisnis pada Ibu Rumah Tangga untuk produk yang bernilai jual.

4. Berpartisipasi dalam mengurangi sampah plastik.

\section{UCAPAN TERIMA KASIH}

Ucapan terimakasih diucapkan kepada:

1. Direktur Politeknik Negeri Samarinda (Polnes) yang telah memberikan pendanaan untuk kegiatan PKM ini.

2. Ketua P3M yang telah mengagendakan kegiatan pengabdian masyarakat di lingkungan dosen Polnes.

3. Ketua Prodi Arsitektur Polnes, staf pengajar, teknisi, staf administrasi dan mahasiswa Prodi Arsitektur yang mendukung langsung kegiatan PKM ini.

4. Ketua Pengurus Daerah 'Aisyiyah Kota Samarinda bersama pengurus
Amal Usaha 'Aisyiyah Kota Samarinda yang telah menyiapkan peserta PKM dan peminjaman aula.

\section{DAFTAR PUSTAKA}

[1]. Fatoni, N., Imanuddin, R., \& Darmawan, A. R. (2017). Pendayagunaan Sampah Menjadi Produk Kerajinan. Jurnal DIMAS, 83-96.

[2]. Hadi, M., Darwin, R., Widiarsih, D., Hidayat, M., Murialti, N., \& Asnawi, M. (2017). Pemanfaatan BarangBarang Bekas Yang Bernilai Ekonomi Bagi Peningkatan Produktivitas Jiwa Entrepreneur Ibu Rumah Tangga Rt.01/Rw.12 Desa Limbungan Kecamatan Rumbai Pesisir. Jurnal UMRI, 1(1), 42-47.

[3]. Iman, R. N. (2017, April 2). Republika.co.id. Retrieved March 25, 2019, from Repoblika.co.id: https://republika.co.id/berita/ekonom i/makro/17/04/02/onrr8w361kerajinan-karung-goni-berdayakanwarga-sekitar.

[4]. Marzuki, F., \& Ali, S. (2018). Memberdayakan Ekonomi Ukm Menyelamatkan Danau Maninjau dari Pencemaran dan Kerusakan Lingkungan. Jurnal Ipteks Terapan, 12(1), 84-93.

[5]. Nurdin, \& Silmi, I. (2014). Faktorfaktor yang Berhubungan dengan Pengelolaan Sampah Organik Rumah Tangga menjadi Kompos di Joang IX Pancahan Kecamatan Rao Kabupaten Pasamu Tahun 2013. Jurnal Ipteks TerapaN, 144-156.

[6]. PemkotSamarinda. (2019). Peraturan Walikota Samarinda No 1 Tahun $2019 \quad$ Pengurangan Penggunaan Kantong Plastik. Samarinda: Pemerintah Kota Samarinda.

[7]. Rochani, A. (2017). Strategi Pengembangan Industri Kreatif Dalam Mewujudkan Kota Cerdas. Jurnal Unissula, 81-93. 
[8]. Sulistiyoningrum1, C. E., Jufrizal, \& Mulia, A. (2017). Go-Scufy:

Redesain Produk Sepatu Wanita Berbahan Karung Goni Menggunakan Metode Quality Function Deployment. Jurnal Ilmiah Teknik Industri, 40-47.

[9]. Widyastuti, U., \& ES, D. P. (2015). Evaluasi Pelatihan (Training) Level Ii Berdasarkan Teori The Four Levels Kirkpatrick. Jurnal Pendidikan Ekonomi dan Bisnis, 3, 119-128. 